\title{
Co-Pyrolysis Cangkang Kelapa Sawit dan Limbah Plastik KEMASAN
}

\author{
Co-pyrolysis of Palm Oil Kernel Shell and Packaging Plastic
}

Sabar Pangihutan Simanungkalit ${ }^{1{ }^{* *}}$ dan Dieni Mansur ${ }^{1}$

${ }^{1}$ Pusat Penelitian Kimia, LIPI, Kawasan Puspiptek - Serpong, Indonesia

1,*Pos-el: saba004@lipi.go.id

\begin{tabular}{|c|c|}
\hline ARTICLE INFO & Abstract \\
\hline $\begin{array}{l}\text { Article history } \\
\text { Received date } \\
20 \text { September } 2018 \\
\text { Received in revised form date } \\
18 \text { July } 2019 \\
\text { Accepted date } \\
29 \text { July } 2019 \\
\text { Available online date } \\
\text { November } 2020\end{array}$ & $\begin{array}{l}\text { In the present study, the co-pyrolysis of biomass waste, i.e. palm kernel } \\
\text { shells (PKS) and industrial packaging plastic waste, namely polyeth- } \\
\text { ylene terephthalate (PET) and polyethylene (PE) were conducted. Prior } \\
\text { to the pyrolysis, the raw materials were analyzed by thermogravimetric } \\
\text { and elemental procedures. The pyrolysis was conducted in a fixed bed } \\
\text { reactor which was heated from room temperature to } 500{ }^{\circ} \mathrm{C} \text { in an } \mathrm{N}_{2} \\
\text { atmosphere with a heating rate of } 10{ }^{\circ} \mathrm{C} / \mathrm{min} \text {. The raw materials were } \\
\text { weighted and mixed together manually with variations of weight } \\
\text { composition ratios between biomass and plastic, i.e. } 100 \% \text { biomass } \\
(100 / 0) ; 90 \% \text { biomass and } 10 \% \text { plastic }(90 / 10) ; 70 \% \text { biomass and } \\
30 \% \text { plastic (70/30); } 50 \% \text { biomass and } 50 \% \text { plastic (50/50); and } 100 \% \\
\text { plastic }(0 / 100) \text {. Then, they were put under pressure to obtain a pellet. } \\
\text { The synergistic effect of biomass and plastic was investigated to see } \\
\text { the difference between the pyrolysis products yields in theory and ex- } \\
\text { periment. The bio-oil products were characterized by several methods } \\
\text { and showed the potential to be used as a fuel. The optimum condition } \\
\text { was obtained from } 50 / 50 \text { weight composition ratio. It was gained } 30 \% \\
\text { improvement of the higher heating value of bio-oil, and the percentage } \\
\text { area of hydrocarbon was contained in bio-oil increased from } 4.68 \% \text { to } \\
53.40 \% \text {. }\end{array}$ \\
\hline
\end{tabular}

Keywords: Co-pyrolysis, Biomass, Plastic waste, Bio-oiln

(C)2020 Widyariset. All rights reserved 


\begin{tabular}{|c|c|}
\hline Kata kunci: & Abstrak \\
\hline $\begin{array}{l}\text { Co-pyrolysis } \\
\text { Biomassa } \\
\text { Limbah plastik } \\
\text { Bio-oil }\end{array}$ & $\begin{array}{l}\text { Dalam penelitian ini dilakukan proses co-pyrolysis limbah biomassa, } \\
\text { yakni cangkang kelapa sawit (CKS) dengan limbah industri plastik } \\
\text { kemasan, jenis polietilen tereptalat (PET), dan polietilen (PE) untuk } \\
\text { meningkatkan yield dan kualitas bio-oil sebagai sumber energi alter- } \\
\text { natif. Penelitian ini ditujukan untuk mengetahui pengaruh proporsi } \\
\text { setiap jenis plastik dalam bahan baku terhadap bio-oil yang dihasilkan. } \\
\text { Sebelum dipirolisis bahan baku tersebut dianalisis termogravimetri dan } \\
\text { elemental. Proses pirolisis dilakukan dalam reaktor unggun tetap yang } \\
\text { dipanaskan dari temperatur ruang hingga } 500{ }^{\circ} \mathrm{C} \text { dalam atmosfer } \mathrm{N} \\
\text { dengan laju pemanasan } 10{ }^{\circ} \mathrm{C} / \text { menit. Bahan baku pirolisis ditimbang dan } \\
\text { dicampur dalam variasi rasio komposisi berat antara biomassa dengan } \\
\text { plastik, yaitu } 100 \% \text { biomassa }(100 / 0) \text {; } 90 \% \text { biomassa dan } 10 \% \text { plastik } \\
\text { (90/10); } 70 \% \text { biomassa dan } 30 \% \text { plastik }(70 / 30) \text {; serta } 50 \% \text { biomassa } \\
\text { dan } 50 \% \text { plastik ( } 50 / 50) \text { dan } 100 \% \text { plastik }(0 / 100) \text {. Selanjutnya, bahan } \\
\text { baku tersebut dibuat dalam bentuk pelet. Efek sinergis antara biomassa } \\
\text { dan plastik diinvestigasi untuk melihat perbedaan yield produk pirolisis } \\
\text { secara teori dan eksperimen. Produk bio-oil dikarakterisasi dengan } \\
\text { beberapa metode dan menunjukkan potensi dapat digunakan sebagai } \\
\text { bahan bakar. Hasil optimum didapatkan pada campuran CKS dan } \\
\text { plastik PET dengan rasio komposisi } 50 / 50 \text {. Dimana nilai kalor bio-oil } \\
\text { meningkat hingga } 30 \% \text { dan persentase area senyawa hidrokarbon dalam } \\
\text { bio-oil meningkat dari } 4,68 \% \text { menjadi } 53,40 \% \text {. }\end{array}$ \\
\hline
\end{tabular}

(C) 2020 Widyariset. All rights reserved

\section{PENDAHULUAN}

Perkembangan dunia industri, modernisasi, dan pertumbuhan penduduk menyebabkan kebutuhan energi semakin meningkat, sedangkan cadangan energi fosil semakin menipis. Salah satu artikel dalam jurnal Energy Policy memperkirakan bahwa persediaan energi fosil dunia akan habis pada tahun 2112 untuk batu bara dan tahun 2042 untuk minyak bumi (Shafiee and Topal 2009). Untuk mengatasinya, maka hingga saat ini terus dilakukan upaya untuk mencari sumber energi alternatif serta mengembangkan teknologi yang memiliki efisiensi tinggi dan ramah lingkungan. Sebagian besar penelitian energi terbarukan memanfaatkan biomassa sebagai bahan baku (Manzano-Agugliaro et al. 2013). Indonesia dengan ketersediaan biomassa yang sangat melimpah memiliki peluang besar menjadi produsen energi alternatif berbasis biomassa.
Beberapa proses termokimia seperti: gasifikasi, torefaksi, pirolisis, dan insinerasi dapat digunakan untuk mengonversi biomassa menjadi energi. Di antara proses konversi termal tersebut, pirolisis dianggap sebagai metode yang paling efisien dan menjanjikan karena rasio produk liquid dan bahan baku yang tinggi (Demirbaş 2002). Pirolisis dapat didefinisikan sebagai proses degradasi material padat (biomassa) dengan memanfaatkan energi panas dalam tekanan atmosfir tanpa adanya oksigen $\left(\mathrm{O}_{2}\right)$ untuk menghasilkan bio-oil (liquid), arang (solid), dan produk gas (Bridgwater, Meier, and Radlein 1999; Cardoso and Ataíde 2013). Salah satu biomassa di Indonesia yang berpotensi untuk dijadikan bahan baku produksi bio-oil adalah cangkang kelapa sawit (CKS), yang merupakan limbah dari industri kelapa sawit. Kandungan lignin yang tinggi, menjadikan CKS sebagai salah satu bahan baku yang terbaik dan menjadi pilihan bagi peneliti dalam 
melakukan penelitian pirolisis biomassa (Huang et al. 2018).

Pirolisis CKS dalam reaktor unggun tetap didapatkan bio-oil maksimum 47,3\% pada temperatur $500^{\circ} \mathrm{C}$ (Abnisa et al. 2011). Sementara itu, dengan menggunakan reaktor unggun terfluidisasi dihasilkan bio-oil maksimum $48,7 \%$ pada temperatur $490{ }^{\circ} \mathrm{C}$ (Kim, Jung, and Kim 2010). Bio-oil dapat langsung digunakan, seperti pada boiler, tungku pembakaran dan turbin untuk menghasilkan energi listrik (Mohan, Pittman, and Steele 2006). Akan tetapi kandungan oksigen dari bio-oil yang cukup tinggi yakni berkisar antara $35-60 \%$ dari berat, membentuk senyawa beroksigen (misalnya: asam, alkohol, aldehida, ester, keton, fenol, oligomer lignin, dll.) (Bridgwater, Meier, and Radlein 1999; Guillain et al. 2009; Oasmaa and Czernik 1999). Hal ini menyebabkan bio-oil bersifat tidak stabil, korosif dan memiliki nilai kalor yang lebih rendah dibandingkan dengan bahan bakar fosil (Oasmaa and Czernik 1999). Oleh karena itu, bio-oil perlu diproses lebih lanjut (upgrading) untuk mendapatkan kualitas yang lebih baik.

Berdasarkan literatur sebelumnya, proses upgrading untuk menghilangkan kandungan oksigen dalam bio-oil dilakukan dengan berbagai macam metode, seperti: hidro-deoksigenasi (HDO), pirolisis berkatalis, perengkahan berkatalis, steam reforming, distilasi molekuler, superkritik fluida, esterifikasi, dan emulsifikasi (Bridgwater, Meier, and Radlein 1999; Joshi and Lawal 2012; Oasmaa and Czernik 1999). Akan tetapi saat ini hanya ada dua proses yang masih dikembangkan, yaitu: hidro-deoksigenasi (HDO) dan perengkahan berkatalis (Toba et al. 2011; Joshi and Lawal 2012). Perkembangan terbaru, upgrading bio-oil dilakukan dengan proses co-pyrolysis atau pirolisis campuran biomassa dengan bahan baku lain yang memiliki kandungan bahan bakar yang lebih tinggi (Uzoejinwa et al. 2018).

Salah satu bahan baku yang berpotensi digunakan sebagai campuran biomassa dalam proses co-pyrolysis adalah plastik. Sebagian besar limbah plastik yang berasal dari aktivitas manusia sehari-hari adalah material polimer sintesis yang merupakan produk turunan dari industri petrokimia. Plastik tersebut kaya akan hidrogen $(\mathrm{H} 2)$ dengan jumlah oksigen (O2) yang sangat sedikit (Miskolczi et al. 2004). Oleh karena itu plastik dapat difungsikan sebagai sumber hidrogen dalam proses degradasi termal biomassa (Dorado, Mullen, and Boateng 2015). Pemanfaatan limbah plastik sebagai bahan baku co-pyrolysis dapat mengurangi volume limbah plastik kemasan yang merupakan limbah plastik terbesar yang ada di tengah masyarakat (Das and Tiwari 2018).

Penelitian co-pyrolysis biomassa dengan limbah plastik telah dilakukan oleh beberapa peneliti. Akan tetapi mekanisme co-pyrolysis biomassa dengan limbah plastik sangat kompleks, sehingga membutuhkan studi lebih lanjut (Guillain et al. 2009). Mayoritas dari studi tersebut memanfaatkan poliolefins, seperti polietilen (PE), polipropilen (PP), dan polistiren (PS) sebagai bahan baku dicampur dengan biomassa yang bervariasi (Sajdak 2017). Oleh karena itu, dalam penelitian ini dilakukan proses co-pyrolysis CKS dengan jenis plastik kemasan yang jarang digunakan dalam proses co-pyrolysis, yaitu polietilen tereptalat (PET). Produk yang diperoleh dibandingkan dengan produk co-pyrolysis CKS dengan plastik kemasan jenis PE. Berbeda dengan publikasi sebelumnya (Simanungkalit et al. 2018), investigasi terhadap efek sinergis dilakukan dalam penelitian ini. Proses pirolisis dilakukan dalam reaktor unggun tetap dengan bahan baku biomassa dan limbah plastik kemasan serta campurannya. Produk liquid (bio-oil) 
dianalisis untuk membandingkan pengaruh proporsi setiap jenis plastik dalam bahan baku.

\section{METODE}

\section{Persiapan dan Karakterisasi Bahan Baku}

Bahan baku biomassa yang digunakan dalam penelitian ini adalah cangkang kelapa sawit (CKS) yang diperoleh dari PTPN-IV Pabatu - Medan (Sumatera Utara - Indonesia). Sedangkan untuk bahan baku plastik adalah limbah industri plastik kemasan dengan jenis polietilen (PE) dan polietilen tereptalat (PET) yang didapatkan dari PT. Amcor Flexible Indonesia (Jakarta - Indonesia). Sebelum digunakan, kedua bahan baku tersebut digiling terlebih dahulu sampai berdimensi panjang dan tinggi $\leq 1 \mathrm{~mm}$, kemudian dilakukan analisis termogravimetri dan elemental.

Analisis elemental dilakukan dengan Leco-CHN 628 berdasarkan metode ASTM D 5373. Untuk mengetahui karakteristik termal kedua bahan baku, maka dilakukan analisis termogravimetri menggunakan LINSEIS STA Platinum Series thermogravimetric analyzer. Dalam analisis tersebut, sampel dengan ukuran berat $10-15 \mathrm{mg}$ dipirolisa dalam atmosfir Nitrogen $\left(\mathrm{N}_{2}\right)$ dari temperatur ruang hingga mencapai $600{ }^{\circ} \mathrm{C}$ dengan laju pemanasan $10{ }^{\circ} \mathrm{C} /$ menit.

Sebelum dipirolisa dalam reaktor unggun tetap, kedua bahan tersebut dibuat pelet berdiameter $20 \mathrm{~mm}$ dengan tinggi 7 $\mathrm{mm}$. Pelet tersebut dibuat dalam beberapa variasi rasio komposisi berat antara biomassa dengan plastik yaitu: $100 \%$ biomassa (100/0); 90\% biomassa dan 10\% plastik (90/10); 70\% biomassa dan 30\% plastik (70/30); serta $50 \%$ biomassa dan $50 \%$ plastik (50/50) dan $100 \%$ plastik (0/100).

\section{Proses Pirolisis}

Setelah analisis termogravimetri selesai dilakukan, maka dilanjutkan dengan proses pirolisis dalam reaktor unggun tetap yang berdiameter $33 \mathrm{~mm}$ dengan panjang $560 \mathrm{~mm}$ dan terbuat dari bahan besi tahan karat kelas 304. Reaktor dipanaskan menggunakan pemanas listrik eksternal yang dilengkapi dengan kontrol dan sensor temperatur (Gambar 1) (Simanungkalit et al. 2018). Sampel berbentuk pelet dengan kisaran berat $20 \mathrm{~g}$ dimasukkan ke dalam reaktor, kemudian dipanaskan dari temperatur ruang hingga $500{ }^{\circ} \mathrm{C}$ dalam atmosfer $\mathrm{N}_{2}$ dengan laju pemanasan $10^{\circ} \mathrm{C} /$ menit.

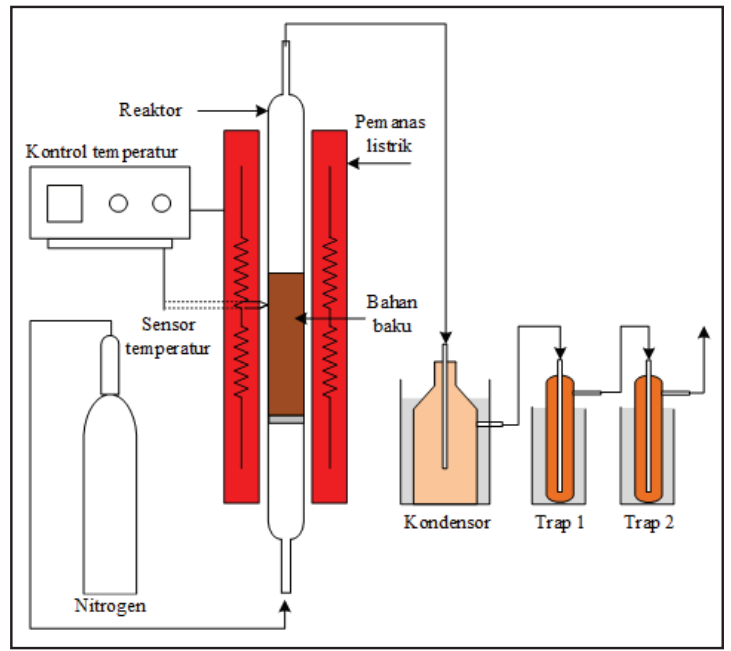

Gambar 1. Proses pirolisis reaktor unggung tetap

Perhitungan neraca massa dilakukan dalam beberapa tahapan (Simanungkalit et al. 2018). Produk liquid (bio-oil dan pyroligneous acid) dikumpulkan dalam kondensor dan trap yang didinginkan menggunakan campuran batu es dan etanol dengan temperatur $\leq 0{ }^{\circ} \mathrm{C}$. Kondensor dan trap dibilas menggunakan diklorometan (DCM) untuk melarutkan bio-oil, sekaligus memisahkan pyroligneous acid (fasa air) yang terkandung dalam produk liquid proses pirolisis. Kemudian bio-oil dengan pyroligneous acid diseparasi menggunakan corong pisah. Bio-oil yang terlarut dalam 
DCM kemudian dievaporasi menggunakan rotary evaporator untuk memisahkan DCM dari bio-oil. Sementara itu, produk solid (char) dari proses co-pyrolysis ditentukan berdasarkan selisih antara berat reaktor sebelum dan sesudah proses. Produk gas dihitung dengan neraca massa keseluruhan.

\section{Efek Sinergis}

Investigasi terhadap efek sinergis antara biomassa dan plastik dalam degradasi termal merupakan salah satu fenomena utama dalam proses co-pyrolysis. Untuk mengetahui efek sinergis tersebut, maka dalam penelitian ini dilakukan perbandingan antara yield produk eksperimen pirolisis dengan yield produk hasil perhitungan secara teoritis sebagai dampak penambahan plastik dalam bahan baku. Yield produk teoritis $(y)$ dihitung berdasarkan proporsi massa setiap bahan baku dalam campuran dan diasumsikan tidak ada interaksi antara uap hasil pirolisis (pers.1) (Martínez et al. 2014). Dimana $\mathrm{w}_{1}$ dan $\mathrm{w}_{2}$ adalah proporsi biomassa dan plastik, sedangkan $\alpha_{1}$ dan $\alpha_{2}$ merupakan yield produk dari pirolisis biomassa dan plastik.

$$
y=w_{1} \cdot \alpha_{1}+w_{2} \cdot \alpha_{2}
$$

\section{Karakterisasi Bio-oil}

Bio-oil yang diperoleh dari proses co-pyrolysis kemudian dianalisis elemental menggunakan Leco-CHN 628 dengan standar ASTM D 5373. Karakterisasi dilanjutkan dengan gas chromatography - mass spectrometry (GC-MS) untuk mengetahui senyawa-senyawa yang terkandung di dalam bio-oil. Senyawa tersebut ditentukan dengan metode semi-kuantitatif dari persentase luas area puncak kromatografi (Kiliç et al. 2014). Analisis GC-MS dilakukan menggunakan kromatografi gas pabrikan Agilent Technology 6890N yang dilengkapi dengan detektor spektometer massa 5975B dengan kolom kapiler HP-5MS (30m x $0,25 \mathrm{~mm} ; \mathrm{d}=0,25 \mu \mathrm{m})$. Sebagai carrier gas digunakan gas helium dengan laju alir yang konstan, yaitu $1 \mathrm{~mL}$ per-menit. Temperatur awal oven $40{ }^{\circ} \mathrm{C}$, dipertahankan selama satu menit kemudian dipanaskan hingga $300{ }^{\circ} \mathrm{C}$ dengan laju pemanasan $10^{\circ} \mathrm{C} /$ menit.

\section{HASIL DAN PEMBAHASAN}

\section{Persiapan dan Karakterisasi Bahan Baku}

Hasil analisis elemental dan perhitungan nilai kalor $(\mathrm{MJ} / \mathrm{kg})$ untuk setiap bahan baku ditunjukkan dalam Tabel 1. Nilai kalor (HHV) dihitung berdasarkan persamaan Dulong (pers.2) (Sun et al. 2010). Dari data tersebut dapat dilihat bahwa bahan baku biomassa cangkang kelapa sawit (CKS) memiliki persentase karbon dan nilai kalor yang paling rendah, sedangkan yang tertinggi adalah bahan baku plastik jenis polietilen (PE).

$$
H H V=0,3383 C+1,422(H-O / 8)
$$

Tabel 1. Analisis elemental bahan baku (wt\%) menggunakan Leco-CHN 628 (ASTM D 5373)

\begin{tabular}{lccc}
\hline & CKS & PET $^{*}$ & PE $^{*}$ \\
\hline $\mathrm{C}$ & 45,72 & 56,81 & 68,63 \\
\hline $\mathrm{H}$ & 5,53 & 4,51 & 7,86 \\
\hline $\mathrm{N}$ & 0,51 & 0,35 & 0,32 \\
\hline $\mathrm{O}^{* *}$ & 48,24 & 38,32 & 23,19 \\
\hline $\mathrm{HHV}(\mathrm{MJ} / \mathrm{kg})$ & 14,75 & 18,82 & 30,27 \\
\hline
\end{tabular}

*Sumber : Simanungkalit et al. 2018

${ }^{* *} \mathrm{O}=100-\mathrm{C}-\mathrm{H}-\mathrm{N}$

Karakteristik termal setiap bahan baku ditunjukkan dalam Gambar 2 melalui kurva thermogravimetric analysis (TGA) dan kurva derivative thermogravimetric (DTG). Pada temperatur $<120{ }^{\circ} \mathrm{C}$ bahan baku CKS sudah mulai terdegradasi karena penguapan kadar air (Gambar 2.a). 
Selanjutnya dalam rentang temperatur 150-225 ${ }^{\circ} \mathrm{C}$ terjadi proses depolimerisasi lambat. Reaksi dekomposisi termal yang berlangsung saat temperatur $225-375{ }^{\circ} \mathrm{C}$ menyebabkan massa sampel CKS berkurang secara drastis. Setelah mencapai 400 ${ }^{\circ} \mathrm{C}$ massa CKS berkurang perlahan dan cenderung tetap setelah mencapai $500{ }^{\circ} \mathrm{C}$. Berdasarkan kenaikan temperatur, proses pirolisis biomassa lignoselulosa seperti CKS, dapat dibagi dalam empat tahap, yaitu: penguapan kadar air dan volatil ringan $\left(<120^{\circ} \mathrm{C}\right)$; degradasi hemiselulosa (220-315 $\left.{ }^{\circ} \mathrm{C}\right)$; dekomposisi lignin dan selulosa $\left(315-400{ }^{\circ} \mathrm{C}\right)$; dan degradasi lig$\operatorname{nin}\left(>450^{\circ} \mathrm{C}\right)$ (Sanchez-Silva et al. 2012).

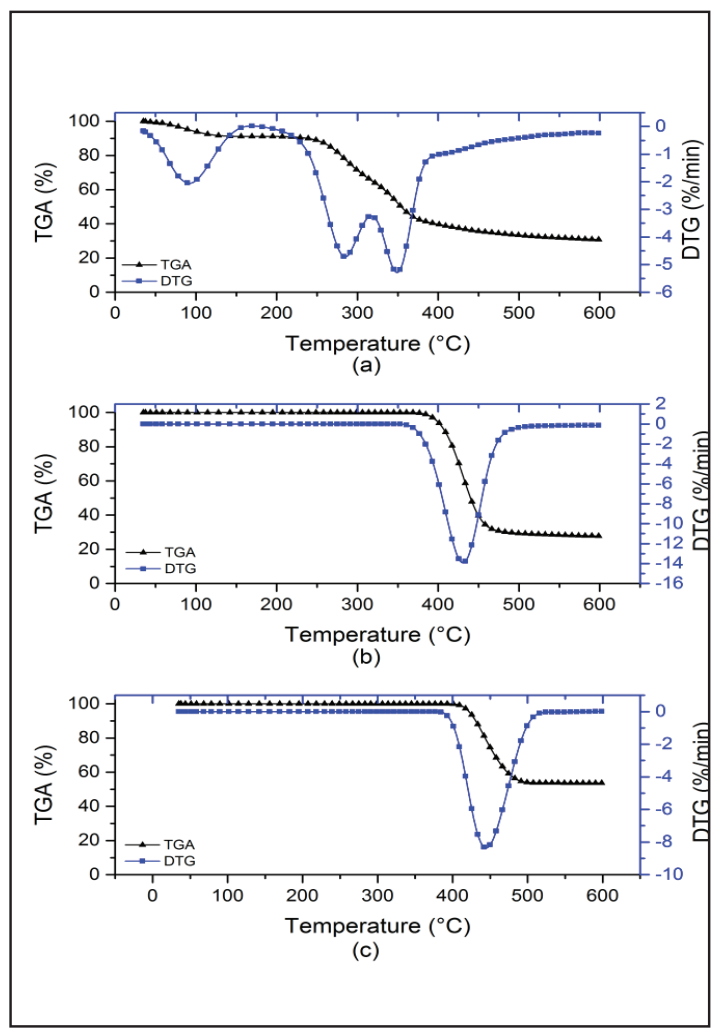

Gambar 2. Analisis termogravimetri bahan baku. (a) CKS; (b) PET; dan (c) PE.
Sementara itu, degradasi termal bahan baku plastik mulai terjadi pada temperatur $\geq 380{ }^{\circ} \mathrm{C}$ untuk PET (Gambar 2.b) dan pada temperatur $\geq 400{ }^{\circ} \mathrm{C}$ untuk PE (Gambar 2.c) (Simanungkalit et al. 2018). Kemudian pengurangan massa kedua bahan baku plastik terjadi dengan drastis hingga mencapai temperatur $500{ }^{\circ} \mathrm{C}$ dan cenderung konstan setelah itu. Berdasarkan hasil analisis TGA di atas, maka ditentukan temperatur akhir untuk eksperimen co-pyrolysis dalam reaktor unggun tetap sebesar $500{ }^{\circ} \mathrm{C}$.

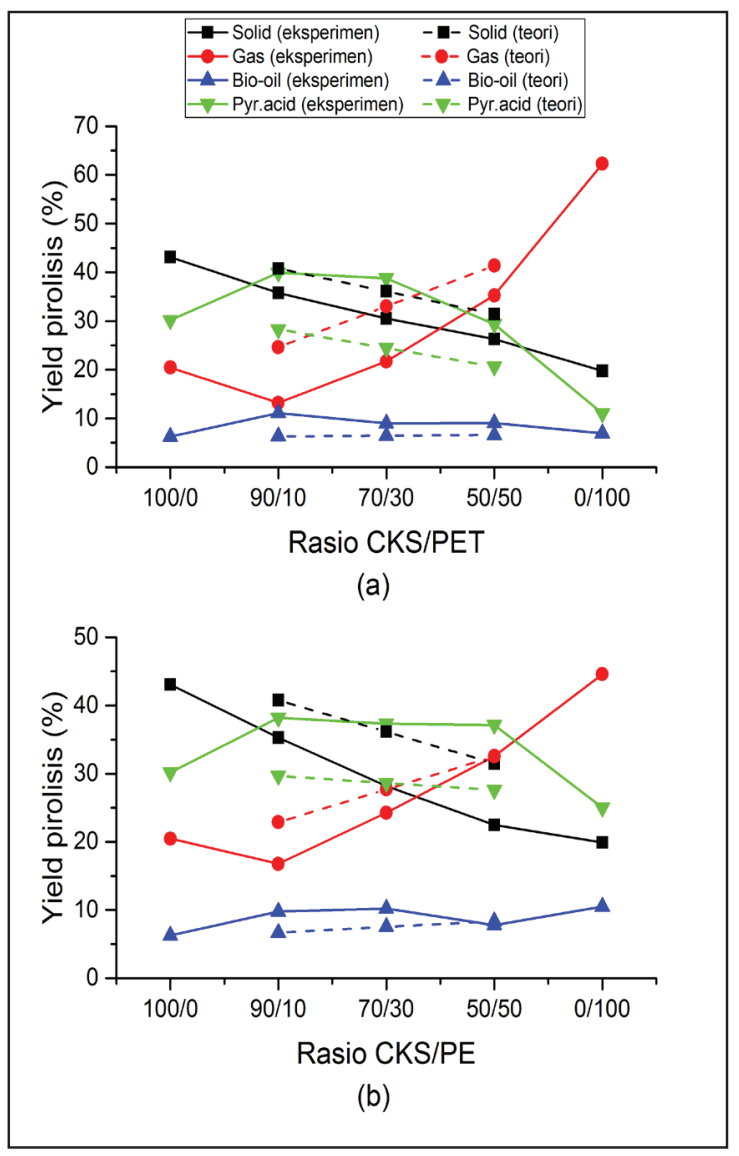

Gambar 3. Yield pirolisis berdasarkan eksperimen dan perhitungan teoritik setiap bahan baku serta campurannya (a) CKS dan PET; (b) CKS dan PE 


\section{Proses Pirolisis}

Produk yield dari proses pirolisis setiap bahan baku biomassa dan plastik serta campurannya dihitung berdasarkan persentase berat yang ditampilkan dalam Gambar 3. Pirolisis murni CKS menghasilkan produk solid (char) terbanyak, yaitu 43,10\%, sedangkan untuk produk gas terbanyak $(62,30 \%)$ diperoleh dari pirolisis plastik PET. Produk liquid dari pirolisis dipisahkan menjadi bio-oil dan pyroligneous acid. Untuk campuran CKS-PET, bio-oil terbanyak dihasilkan pada rasio 90/10 sebesar $11,12 \%$, sedangkan persentase terbesar bio-oil hasil pirolisis campuran CKS-PE adalah $10,21 \%$ pada rasio $70 / 30$. Sementara untuk pyroligneous acid terbesar diperoleh dari pirolisis CKS-PET (90/10) sebesar $39,95 \%$.

Eksperimen pirolisis campuran biomassa dan plastik (co-pyrolysis) menunjukkan perubahan pada persentase produk. Secara keseluruhan, semakin besar persentase plastik dalam bahan baku, maka persentase produk solid (char) menurun, sedangkan persentase produk gas bertambah besar dan bio-oil berfluktuasi. Hal ini disebabkan oleh tingginya kandungan bahan volatil dalam plastik (Abnisa, Mohd, and Wan 2014).

\section{Efek Sinergis}

Efek sinergi antara biomassa dan plastik dalam proses co-pyrolysis dapat diketahui dari selisih antara yield produk eksperimen pirolisis dengan yield produk hasil perhitungan secara teoritis (pers.1). Jika positif, maka dapat dikatakan bahwa proses co-pyrolysis memiliki kontribusi yang signifikan terhadap konversi termal bahan baku. Apabila negatif, maka bisa disimpulkan bahwa efek sinergi tidak terjadi (Suelves, La, and Moliner 2002). Untuk campuran CKS-PET dan campuran CKSPE (Gb.3) efek sinergi positif terjadi pada yield liquid produk (bio-oil dan pyroligneous acid), sedangkan untuk yield produk solid dan gas didapatkan efek sinergi yang negatif. Kandungan polyolefinic polymers dalam bahan baku plastik menyebabkan peningkatan konversi termal yang mengarah kepada naiknya yield produk liquid dalam proses co-pyrolysis (Bozkurt, Tosun, and Canel 2017).

Tabel 2. Hasil analisis elemental bio-oil hasil co-pyrolysis menggunakan Leco-CHN 628 (ASTM D 5373)

\begin{tabular}{|c|c|c|c|c|c|c|c|c|c|}
\hline & \multirow{2}{*}{ CKS } & \multirow{2}{*}{ PET $^{*}$} & \multirow{2}{*}{$\mathrm{PE}^{*}$} & \multicolumn{3}{|c|}{ CKS/PET ratio } & \multicolumn{3}{|c|}{ CKS/PE ratio } \\
\hline & & & & $90 / 10$ & $70 / 30$ & $50 / 50$ & $90 / 10$ & $70 / 30$ & $50 / 50$ \\
\hline $\mathrm{C}(\mathrm{wt} \%)$ & 64,73 & 81,61 & 74,21 & 65,03 & 69,31 & 72,37 & 64,94 & 65,37 & 69,66 \\
\hline $\mathrm{H}$ (wt\%) & 6,68 & 12,83 & 7,98 & 6,64 & 8,29 & 9,13 & 6,65 & 7,97 & 8,72 \\
\hline $\mathrm{N}(w t \%)$ & 0,90 & 0,07 & 0,14 & 0,54 & 0,42 & 0,36 & 0,53 & 0,31 & 0,26 \\
\hline $\mathrm{O}(\mathrm{wt} \%)^{* *}$ & 27,69 & 5,49 & 17,66 & 27,80 & 21,98 & 18,15 & 27,88 & 26,35 & 21,36 \\
\hline $\mathrm{HHV}(\mathrm{MJ} / \mathrm{kg})$ & 26,47 & 44,87 & 33,32 & 26,50 & 31,32 & 34,23 & 26,47 & 28,76 & 32,17 \\
\hline
\end{tabular}


Tabel 3. Daftar senyawa yang terkandung dalam bio-oil berdasarkan analisis GC-MS (\% area)

\begin{tabular}{|c|c|c|c|c|c|c|c|c|c|c|}
\hline \multirow{2}{*}{ Compounds } & \multirow{2}{*}{ Formula } & \multirow{2}{*}{ CKS } & \multirow{2}{*}{ PET* $^{*}$} & \multirow{2}{*}{$\mathrm{PE}^{*}$} & \multicolumn{3}{|c|}{ Rasio berat CKS/PET } & \multicolumn{3}{|c|}{ Rasio berat PKS/PE } \\
\hline & & & & & $90 / 10$ & $70 / 30$ & $50 / 50$ & $90 / 10$ & $70 / 30$ & $50 / 50$ \\
\hline \multicolumn{11}{|l|}{ Phenol derivatives } \\
\hline Phenol & $\mathrm{C}_{6} \mathrm{H}_{6} \mathrm{O}$ & 52,79 & & & 28,59 & 22,16 & 8,12 & 30,78 & 28,45 & 11,27 \\
\hline Phenol, 2-methyl- & $\mathrm{C}_{7} \mathrm{H}_{8} \mathrm{O}$ & & & & & & & 0.71 & & \\
\hline Phenol, 2-methoxy- & $\mathrm{C}_{7} \mathrm{H}_{8} \mathrm{O}_{2}$ & 4,42 & & & 2,91 & 1,45 & & 1,5 & 2,29 & 1,51 \\
\hline Phenol, 4-ethyl-2-methoxy- & $\mathrm{C}_{9} \mathrm{H}_{12} \mathrm{O}_{2}$ & 4,74 & & & 2,3 & & & & 2,14 & 1,23 \\
\hline Phenol, 2,6-dimethoxy- & $\mathrm{C}_{8} \mathrm{H}_{10} \mathrm{O}_{3}$ & 5,43 & & & 4,11 & 2,27 & & 1,98 & 2,77 & 1,86 \\
\hline $\begin{array}{l}\text { Phenol, 2-methoxy-4-(1-pro- } \\
\text { penyl)- }\end{array}$ & $\mathrm{C}_{10} \mathrm{H}_{12} \mathrm{O}_{2}$ & & & & 1,48 & & & 0,73 & & \\
\hline $\begin{array}{l}\text { Phenol, 2,6-dimethoxy-4-(2-pro- } \\
\text { penyl)- }\end{array}$ & $\mathrm{C}_{11} \mathrm{H}_{14} \mathrm{O}_{3}$ & 3,59 & & & 2,22 & & & & 1,75 & \\
\hline 2-Methoxy-4-vinylphenol & $\mathrm{C}_{9} \mathrm{H}_{10} \mathrm{O}_{2}$ & & & & 1,68 & & & & & \\
\hline $\begin{array}{l}\text { 3,5-Dimethoxy-4-hydroxytol- } \\
\text { uene }\end{array}$ & $\mathrm{C}_{9} \mathrm{H}_{12} \mathrm{O}_{2}$ & 1,79 & & & 1,48 & & & & & \\
\hline$\Sigma$ Total & & 72,76 & 0 & 0 & 44,77 & 25,88 & 8,12 & 35,7 & 37,4 & 15,87 \\
\hline \multicolumn{11}{|l|}{ Benzene derivatives } \\
\hline Biphenyl & $\mathrm{C}_{12} \mathrm{H}_{10}$ & & 1,33 & 1,62 & & & & & & 0,88 \\
\hline$\Sigma$ Total & & 1,79 & 1,33 & 1,62 & 0 & 0 & 0 & 0 & 0 & 0,88 \\
\hline \multicolumn{11}{|l|}{ PAH and derivatives } \\
\hline 9H-fluorene & $\mathrm{C}_{13} \mathrm{H}_{10}$ & & 0,76 & & & & & & & \\
\hline 9H-fluorene, 2-methyl- & $\mathrm{C}_{14} \mathrm{H}_{12}$ & & 0,28 & & & & & & & \\
\hline$\Sigma$ Total & & 0 & 1,04 & 0 & 0 & 0 & 0 & 0 & 0 & 0 \\
\hline \multicolumn{11}{|l|}{ Ketones } \\
\hline Benzophenone & $\mathrm{C}_{13} \mathrm{H}_{10} \mathrm{O}$ & & 0,39 & & & & & & & \\
\hline $\begin{array}{c}\text { 1,2-Cyclopentanedione, } \\
\text { 3-methyl- }\end{array}$ & $\mathrm{C}_{6} \mathrm{H}_{8} \mathrm{O}_{2}$ & & & & & & & 1,35 & 1,48 & \\
\hline Acetophenone & $\mathrm{C}_{8} \mathrm{H}_{8} \mathrm{O}$ & & & & & & & & 1,35 & 1,42 \\
\hline$\Sigma$ Total & & 0 & 0,39 & 0 & 0 & 0 & 0 & 1,35 & 2,83 & 1,42 \\
\hline \multicolumn{11}{|l|}{ Alkanes } \\
\hline Eicosane & $\mathrm{C}_{20} \mathrm{H}_{42}$ & 4,68 & & 5,56 & 2,66 & 8,98 & 6,04 & 4,94 & 1,49 & 10,19 \\
\hline Heptadecane & $\mathrm{C}_{17} \mathrm{H}_{36}$ & & 3,51 & 0,99 & & 2,1 & 1,74 & 1,41 & & 1,71 \\
\hline Cyclotetracosane & $\mathrm{C}_{24} \mathrm{H}_{48}$ & & 4,04 & & & & & & & \\
\hline Tridecane & $\mathrm{C}_{13} \mathrm{H}_{28}$ & & & & & & & & & 0,77 \\
\hline Hexadecane & $\mathrm{C}_{16} \mathrm{H}_{34}$ & & 2,65 & 0,94 & & 2,12 & 1,63 & & & 1,55 \\
\hline Octadecane & $\mathrm{C}_{18} \mathrm{H}_{38}$ & & 4,4 & 1 & & 1,31 & 1,47 & & & 1,37 \\
\hline Heneicosane & $\mathrm{C}_{21} \mathrm{H}_{44}$ & & & & 1,81 & 2,53 & & & 1,22 & 1,6 \\
\hline Cyclopentadecane & $\mathrm{C}_{15} \mathrm{H}_{30}$ & & & & & 3,08 & & & & 1,35 \\
\hline Tridecane & $\mathrm{C}_{13} \mathrm{H}_{28}$ & & 0,49 & & & & & & & \\
\hline Pentadecane & $\mathrm{C}_{15} \mathrm{H}_{32}$ & & & 1,14 & & & & & & \\
\hline Nonadecane & $\mathrm{C}_{19} \mathrm{H}_{40}$ & & 5,16 & 3,41 & & 1,02 & & & & 0,84 \\
\hline Triacontane & $\mathrm{C}_{30} \mathrm{H}_{62}$ & & & & & & 5,55 & & & \\
\hline Tetradecane & $\mathrm{C}_{14} \mathrm{H}_{30}$ & & 0,55 & & & & 1,14 & & & 0,72 \\
\hline Cyclopropane & $\mathrm{C}_{3} \mathrm{H}_{6}$ & & & & & & 1 & & & \\
\hline Tritetracontane & $\mathrm{C}_{43} \mathrm{H}_{88}$ & & & & & & 5,49 & & & \\
\hline Dodecane & $\mathrm{C}_{12} \mathrm{H}_{26}$ & & & & & & & & & 0,49 \\
\hline
\end{tabular}




\begin{tabular}{|c|c|c|c|c|c|c|c|c|c|c|}
\hline \multirow{2}{*}{ Compounds } & \multirow{2}{*}{ Formula } & \multirow{2}{*}{ CKS } & \multirow{2}{*}{ PET $^{*}$} & \multirow{2}{*}{$\mathrm{PE}^{*}$} & \multicolumn{3}{|c|}{ Rasio berat CKS/PET } & \multicolumn{3}{|c|}{ Rasio berat PKS/PE } \\
\hline & & & & & $90 / 10$ & $70 / 30$ & $50 / 50$ & $90 / 10$ & $70 / 30$ & $50 / 50$ \\
\hline Hexacosane & $\mathrm{C}_{26} \mathrm{H}_{54}$ & & & & & & & & & 2,6 \\
\hline$\Sigma$ Total & & 4,68 & 20,8 & 13,04 & 4,47 & 21,14 & 24,06 & 6,35 & 2,71 & 23,19 \\
\hline \multicolumn{11}{|l|}{ Acids and esters } \\
\hline Benzoic acid & $\mathrm{C}_{7} \mathrm{H}_{6} \mathrm{O}_{2}$ & & 18,73 & 54,74 & 27,69 & 4,82 & & 24,02 & 18,46 & 26,43 \\
\hline Benzoic acid, methyl ester & $\mathrm{C}_{8} \mathrm{H}_{8} \mathrm{O}_{2}$ & & & & & & & 2,74 & 5,35 & 5,68 \\
\hline $\begin{array}{l}\text { 1,4-Benzenedicarboxylic } \\
\text { acid, dimethyl ester }\end{array}$ & $\mathrm{C}_{10} \mathrm{H}_{10} \mathrm{O}_{4}$ & 7,36 & 2,71 & & 2,21 & 9,07 & 5,75 & & 12,48 & 8,19 \\
\hline $\mathrm{n}$-Hexadecanoic acid & $\mathrm{C}_{16} \mathrm{H}_{32} \mathrm{O}_{2}$ & & 0,45 & & & & & & & \\
\hline Benzoic acid, 4-methyl- & $\mathrm{C}_{8} \mathrm{H}_{8} \mathrm{O}_{2}$ & & & & & & & 2,84 & & \\
\hline $\begin{array}{c}\text { 1,4-Benzenedicarboxylic acid, } \\
\text { ethyl methyl ester }\end{array}$ & $\mathrm{C}_{11} \mathrm{H}_{12} \mathrm{O}_{4}$ & & & & & & & 10,27 & 3,31 & \\
\hline 4-Ethylbenzoic acid & $\mathrm{C}_{9} \mathrm{H}_{10} \mathrm{O}_{2}$ & & 0,76 & & & & & & & \\
\hline $\begin{array}{c}\text { Benzoic acid, 4-acetyl-, methyl } \\
\text { ester }\end{array}$ & $\mathrm{C}_{10} \mathrm{H}_{10} \mathrm{O}_{3}$ & & 0,24 & & & & & & & \\
\hline $\begin{array}{l}\text { Trichloroacetic acid, pentadecyl } \\
\text { ester }\end{array}$ & $\mathrm{C}_{17} \mathrm{H}_{31} \mathrm{Cl}_{3} \mathrm{O}_{2}$ & & & & & & & & & 0,77 \\
\hline $\begin{array}{l}\text { Dichloroacetic acid, } \\
\text { heptadecyl ester }\end{array}$ & $\mathrm{C}_{19} \mathrm{H}_{36} \mathrm{Cl}_{2} \mathrm{O}_{2}$ & & & & & & & & & 1,85 \\
\hline $\begin{array}{l}\text { Pentadecafluorooctanoic } \\
\text { acid, octa decyl ester }\end{array}$ & $\mathrm{C}_{26} \mathrm{H}_{37} \mathrm{~F}_{15} \mathrm{O}_{2}$ & 3,32 & & & & 9,36 & & & 0,83 & 1,9 \\
\hline $\begin{array}{c}\text { Pentafluoropropionic acid, } \\
\text { pentadecyl ester }\end{array}$ & $\mathrm{C}_{18} \mathrm{H}_{31} \mathrm{~F}_{5} \mathrm{O}_{2}$ & & & & & & & 0,54 & & \\
\hline$\Sigma$ Total & & 10,68 & 22,89 & 54,74 & 29,9 & 23,25 & 5,75 & 40,41 & 40,43 & 44,82 \\
\hline \multicolumn{11}{|l|}{ Alkenes } \\
\hline 1,13-Tetradecadiene & $\mathrm{C}_{14} \mathrm{H}_{26}$ & & 0,4 & & & & & & & \\
\hline 1,19-Eicosadiene & $\mathrm{C}_{20} \mathrm{H}_{38}$ & & 1,6 & & & & & & & \\
\hline 1-Decene & $\mathrm{C}_{10} \mathrm{H}_{20}$ & & 0,2 & & & & & & & \\
\hline 1-Dodecene & $\mathrm{C}_{12} \mathrm{H}_{24}$ & & 2,14 & & & 1,02 & & & & 2,44 \\
\hline 1-Eicosene & $\mathrm{C}_{20} \mathrm{H}_{40}$ & & & & & & & 1,31 & & \\
\hline 1-Heptadecene & $\mathrm{C}_{17} \mathrm{H}_{34}$ & & 1,56 & 1,24 & & & 1,7 & 0,56 & & \\
\hline 1-Hexacosene & $\mathrm{C}_{26} \mathrm{H}_{52}$ & & 10,16 & 11,19 & & 3,71 & 4,2 & 1,4 & & \\
\hline 1-Nonadecene & $\mathrm{C}_{19} \mathrm{H}_{38}$ & & 5,08 & 4,48 & & 2,5 & 8,05 & 0,56 & & 0,91 \\
\hline 1-Nonene & $\mathrm{C}_{9} \mathrm{H}_{18}$ & & & & & & & & & \\
\hline 1-Octadecene & $\mathrm{C}_{18} \mathrm{H}_{36}$ & & 1,69 & 1,44 & & 1,52 & 2,01 & & & \\
\hline 1-Pentadecene & $\mathrm{C}_{15} \mathrm{H}_{30}$ & & 1,22 & 0,95 & & 1,88 & 1,53 & & & 2,31 \\
\hline 1-Tetradecene & $\mathrm{C}_{14} \mathrm{H}_{28}$ & & 1,13 & & & & & & & 1,33 \\
\hline 1-Tricosene & $\mathrm{C}_{23} \mathrm{H}_{46}$ & & 12,16 & & & & 5,28 & & & \\
\hline 1-Tridecene & $\mathrm{C}_{13} \mathrm{H}_{26}$ & & 1,67 & & & & & & & 0,86 \\
\hline 1-Undecene & $\mathrm{C}_{11} \mathrm{H}_{22}$ & & 0,57 & & & & & & & \\
\hline 5-Eicosene & $\mathrm{C}_{20} \mathrm{H}_{40}$ & & & & & & & & & \\
\hline Cetene & $\mathrm{C}_{16} \mathrm{H}_{32}$ & & 1,59 & 1,26 & & & 1,77 & & & 1,34 \\
\hline Nonadecene & $\mathrm{C}_{19} \mathrm{H}_{38}$ & & & & & & 1,76 & & & \\
\hline Tetradecene & $\mathrm{C}_{14} \mathrm{H}_{28}$ & & & & & & 3,04 & & & \\
\hline$\Sigma$ Total & & 0 & 41,17 & 20,56 & 0 & 10,63 & 29,34 & 3,83 & 0 & 9,19 \\
\hline
\end{tabular}

${ }^{{ }^{*}}$ Sumber: Simanungkalit et al. 2018 


\section{Karakterisasi Bio-oil}

Tabel 2 menunjukkan hasil analisis elemental bio-oil hasil pirolisis bahan baku biomassa (CKS), plastik (PET dan PE) serta campuran biomassa dengan plastik dalam variasi rasio komposisi berat. Secara umum, penambahan plastik ke dalam biomassa sebagai bahan baku pirolisis meningkatkan persentase elemen karbon $(\mathrm{C})$ dan hidrogen $(\mathrm{H})$ dari bio-oil serta menurunkan persentase Oksigen (O) (Abnisa et al. 2013). Hal ini menyebabkan nilai kalor bio-oil hasil pirolisis campuran biomassa dan plastik lebih tinggi daripada bio-oil dari pirolisis biomassa. Untuk campuran CKS dengan kedua jenis plastik, peningkatan nilai kalor bio-oil terbesar didapat pada rasio berat 50/50. Dimana nilai kalor campuran CKS-PET dan CKSPE masing-masing meningkat s.d. 30 dan $22 \%$. Hasil serupa juga didapatkan dalam penelitian sebelumnya yang memanfaatkan plastik PET dan PE sebagai bahan baku. Proses co-pyrolysis jerami dengan PET dapat meningkatkan nilai kalor bio-oil s.d. 60\% (Izzatie et al. 2017), sementara itu nilai kalor bio-oil hasil co-pyrolysis kulit kentang dengan dengan plastik jenis PE naik dari $32 \mathrm{MJ} / \mathrm{kg}$ menjadi 45,61 MJ/kg (Rutkowski and Kubacki 2006).

Tujuan dari analisis GC-MS adalah untuk mengetahui pengaruh persentase komposisi plastik dalam bahan baku pirolisis terhadap perubahan senyawa yang terkandung dalam bio-oil. Tabel 3 merupakan data analisis GC-MS (\% area) dari bio-oil hasil pirolisis bahan baku biomassa CKS, plastik PET dan PET, serta campurannya dalam variasi rasio komposisi berat. Senyawa yang teridentifikasi dalam bio-oil diklasifikasikan dalam: senyawa phenols, benzenes, PAH, ketones, alkanes, acids - esters, dan alkenes (Rutkowski and Kubacki 2006). Senyawa utama dalam bio-oil hasil pirolisis CKS adalah senyawa teroksigenasi yakni phenols (72.76\%), yang berasal dari perengkahan lignin yang merupakan komponen utama dari CKS (Asadieraghi, Mohd, and Wan 2015). Sementara itu, bio-oil hasil pirolisis plastik didominasi oleh senyawa hidrokarbon Alkenes $(41,17 \%)$ untuk PET dan Acids-esters (54,74\%) untuk PE.

Selanjutnya dari data yang ada di Tabel 3, semakin besar proporsi plastik dalam bahan baku pirolisis, maka senyawa phenols dalam bio-oil akan menurun sedangkan senyawa hidrokarbon seperti Alkanes dan Alkenes meningkat. Senyawa hidrokarbon tersebut berkisar antara $\mathrm{C}_{3}$ sampai $\mathrm{C}_{43}$, sehingga bio-oil tersebut berpotensi digunakan sebagai bahan bakar (Lu et al. 2012)CCl4, CS2, benzene and $\mathrm{CH} 2 \mathrm{Cl} 2$. In total, 167 organic species were identified with GC/MS in the extracts and classified into alkanes, alcohols, hydroxybenzenes, alkoxybenzenes, dioxolanes, aldehydes, ketones, carboxylic acids, esters, nitrogen-containing organic compounds and other species. The benzene ring-containing species (BRCCs. Bio-oil dengan kandungan senyawa hidrokarbon terbanyak didapat pada campuran rasio berat $50 \%$ biomassa dan $50 \%$ plastik. Senyawa hidrokarbon dalam bio-oil naik dari 4,68-53,4\% untuk campuran CKS-PET dan hingga 32,38\% untuk campuran CKSPE. Dalam hal ini plastik berfungsi sebagai donor hidrokarbon dalam proses pirolisis campuran biomassa dan plastik (co-pyrolysis) (Chattopadhyay et al. 2016). Hasil yang sama didapatkan dalam co-pyrolysis CKS dengan plastik polistiren, dimana persentase area senyawa hidrokarbon dalam bio-oil naik hingga mencapai 39,59\% (Abnisa et al. 2013).

\section{KESIMPULAN}

Proses co-pyrolysis campuran biomassa (cangkang kelapa sawit) dengan limbah plastik (polietilen dan polietilen tereptalat) 
dapat menghasilkan bio-oil dengan kualitas yang lebih baik dibandingkan dengan biooil hasil pirolisis biomassa, dan berpotensi diaplikasikan sebagai bahan bakar. Nilai kalor dan kandungan senyawa hidrokarbon dalam bio-oil meningkat seiring bertambahnya proporsi plastik dalam bahan baku pirolisis.

\section{UCAPAN TERIMA KASIH}

Penulis mengucapkan terima kasih kepada Gabriel Kristian dan Ibnu Adulah yang telah membantu penulis dalam melakukan eksperimen, serta kepada Yayang Ade Suprana untuk suplai bahan baku plastik limbah industri.

\section{DAFTAR ACUAN}

Abnisa, Faisal, W. M.A.W. Daud, W. N.W. Husin, and J. N. Sahu. 2011. "Utilization Possibilities of Palm Shell as a Source of Biomass Energy in Malaysia by Producing Bio-Oil in Pyrolysis Process." Biomass and Bioenergy 35 (5): 1863-72. https://doi.org/10.1016/j. biombioe.2011.01.033.

Abnisa, Faisal, Wan Mohd, and Ashri Wan. 2014. "A Review on Co-Pyrolysis of Biomass: An Optional Technique to Obtain a High-Grade Pyrolysis Oil." Energy Conversion and Management 87: 71-85. https://doi.org/10.1016/j. enconman.2014.07.007.

Abnisa, Faisal, W. M.A. Wan Daud, Sujahta Ramalingam, Muhamad Naqiuddin Bin M. Azemi, and J. N. Sahu. 2013. "Co-Pyrolysis of Palm Shell and Polystyrene Waste Mixtures to Synthesis Liquid Fuel." Fuel 108: 311-18. https:// doi.org/10.1016/j.fuel.2013.02.013.

Asadieraghi, Masoud, Wan Mohd, and Ashri Wan. 2015. "Journal of Analytical and Applied Pyrolysis In-Depth Investigation on Thermochemical Characteristics of Palm Oil Biomasses as Potential Biofuel Sources." Journal of Analytical and Applied Pyrolysis 115: 379-91. https:// doi.org/10.1016/j.jaap.2015.08.017.
Bozkurt, Pinar Acar, Onur Tosun, and Muammer Canel. 2017. "The Synergistic Effect of Co-Pyrolysis of Oil Shale and Low Density Polyethylene Mixtures and Characterization of Pyrolysis Liquid." Journal of the Energy Institute 90 (3): 355-62. https://doi.org/10.1016/j. joei.2016.04.007.

Bridgwater, Anthony V., D. Meier, and D. Radlein. 1999. "An Overview of Fast Pyrolysis of Biomass." Organic Geochemistry 30 (12): 1479-93. https://doi. org/10.1016/S0146-6380(99)00120-5.

Cardoso, C. R., and C. H. Ataíde. 2013. "Analytical Pyrolysis of Tobacco Residue: Effect of Temperature and Inorganic Additives." Journal of Analytical and Applied Pyrolysis 99: 49-57. https://doi. org/10.1016/j.jaap.2012.10.029.

Chattopadhyay, Jayeeta, T. S. Pathak, R. Srivastava, and A. C. Singh. 2016. "Catalytic Co-Pyrolysis of Paper Biomass and Plastic Mixtures (HDPE (High Density Polyethylene), PP (Polypropylene) and PET (Polyethylene Terephthalate)) and Product Analysis." Energy 103: 513-21. https://doi.org/10.1016/j.energy.2016.03.015.

Das, Pallab, and Pankaj Tiwari. 2018. "Valorization of Packaging Plastic Waste by Slow Pyrolysis." Resources, Conservation and Recycling 128 (September 2017): 69-77. https://doi.org/10.1016/j. resconrec.2017.09.025.

Demirbaș, Ayhan. 2002. "Analysis of Liquid Products from Biomass via Flash Pyrolysis." Energy Sources 24 (4): 337-45. https://doi. org/10.1080/00908310252888718.

Dorado, Christina, Charles A. Mullen, and Akwasi A. Boateng. 2015. "Origin of Carbon in Aromatic and Olefin Products Derived from HZSM-5 Catalyzed Co-Pyrolysis of Cellulose and Plastics via Isotopic Labeling." Applied Catalysis B: Environmental 162: 338-45. https:// doi.org/10.1016/j.apcatb.2014.07.006. 
Guillain, Mauviel, Kies Fairouz, Sans Rene Mar, Ferrer Monique, and Lédé Jacques. 2009. "Attrition-Free Pyrolysis to Produce Bio-Oil and Char." Bioresource Technology 100 (23): 6069-75. https:// doi.org/10.1016/j.biortech.2009.06.085.

Huang, Yanqin, Huacai Liu, Hongyou Yuan, Hao Zhan, Xiuzheng Zhuang, Song Yuan, Xiuli Yin, and Chuangzhi Wu. 2018. "Relevance between Chemical Structure and Pyrolysis Behavior of Palm Kernel Shell Lignin." Science of the Total Environment 633: 785-95. https://doi. org/10.1016/j.scitotenv.2018.03.238.

Joshi, Narendra, and Adeniyi Lawal. 2012. "Hydrodeoxygenation of Pyrolysis Oil in a Microreactor." Chemical Engineering Science 74: 1-8. https://doi. org/10.1016/j.ces.2012.01.052.

Kiliç, Murat, Ayşe Eren Pütün, Başak Burcu Uzun, and Ersan Pütün. 2014. "Converting of Oil Shale and Biomass into Liquid Hydrocarbons via Pyrolysis." Energy Conversion and Management 78: 461-67. https://doi.org/10.1016/j. enconman.2013.11.002.

Kim, Seon-jin, Su-hwa Jung, and Joo-sik Kim. 2010. "Bioresource Technology Fast Pyrolysis of Palm Kernel Shells : Influence of Operation Parameters on the Bio-Oil Yield and the Yield of Phenol and Phenolic Compounds." Bioresource Technology 101 (23): 9294-9300. https://doi. org/10.1016/j.biortech.2010.06.110.

Lu, Yao, Xian Yong Wei, Jing Pei Cao, Peng Li, Fang Jing Liu, Yun Peng Zhao, Xing Fan, et al. 2012. "Characterization of a Bio-Oil from Pyrolysis of Rice Husk by Detailed Compositional Analysis and Structural Investigation of Lignin." Bioresource Technology 116: 114-19. https://doi.org/10.1016/j. biortech.2012.04.006.

Manzano-Agugliaro, F., A. Alcayde, F. G. Montoya, A. Zapata-Sierra, and C. Gil. 2013. "Scientific Production of Renewable Energies Worldwide: An Overview." Renewable and Sustainable Energy Reviews 18: 134-43. https://doi. org/10.1016/j.rser.2012.10.020.
Martínez, Juan D., Alberto Veses, Ana M. Mastral, Ramón Murillo, Maria V. Navarro, Neus Puy, Anna Artigues, Jordi Bartrolí, and Tomás García. 2014. "Co-Pyrolysis of Biomass with Waste Tyres: Upgrading of Liquid Bio-Fuel." Fuel Processing Technology 119: 263-71. https://doi. org/10.1016/j.fuproc.2013.11.015.

Miskolczi, N., L. Bartha, G. Deák, and B. Jóver. 2004. "Thermal Degradation of Municipal Plastic Waste for Production of Fuel-like Hydrocarbons." Polymer Degradation and Stability 86 (2): 357-66. https://doi.org/10.1016/j. polymdegradstab.2004.04.025.

Mohan, Dinesh, Charles U. Pittman, and Philip H. Steele. 2006. "Pyrolysis of Wood/Biomass for Bio-Oil: A Critical Review." Energy and Fuels. https://doi. org/10.1021/ef0502397.

Oasmaa, Anja, and Stefan Czernik. 1999. "Fuel Oil Quality of Biomass Pyrolysis Oils s State of the Art for the End Users," 914-21.

Rutkowski, Piotr, and Andrzej Kubacki. 2006. "Influence of Polystyrene Addition to Cellulose on Chemical Structure and Properties of Bio-Oil Obtained during Pyrolysis" 47: 716-31. https://doi. org/10.1016/j.enconman.2005.05.017.

Sajdak, Marcin. 2017. "Impact of Plastic Blends on the Product Yield from Co-Pyrolysis of Lignin-Rich Materials." Journal of Analytical and Applied Pyrolysis 124: 415-25. https://doi.org/10.1016/j. jaap.2017.03.002.

Sanchez-Silva, L., D. López-González, J. Villaseñor, P. Sánchez, and J. L. Valverde. 2012. "Thermogravimetric-Mass Spectrometric Analysis of Lignocellulosic and Marine Biomass Pyrolysis." Bioresource Technology 109: 163-72. https:// doi.org/10.1016/j.biortech.2012.01.001.

Series, Conference. 2017. "Co-Pyrolysis of Rice Straw and Polyethylene Terephthalate ( PET ) Using a Fixed Bed Drop Type Pyrolyzer Co-Pyrolysis of Rice Straw and Polyethylene Terephthalate ( PET ) Using a Fixed Bed Drop Type Pyrolyzer," 0-7. 
Shafiee, Shahriar, and Erkan Topal. 2009. "When Will Fossil Fuel Reserves Be Diminished?" Energy Policy 37 (1): 181-89. https://doi.org/10.1016/j.enpol.2008.08.016.

Simanungkalit, Sabar Pangihutan, Dieni Mansur, and Muhammad Arifuddin Fitriady. 2018. "Effect of Plastic Blends on Slow Pyrolysis of Oil Palm Empty Fruit Bunch." AIP Conference Proceedings 2024 (November). https://doi. org/10.1063/1.5064289.

Suelves, I, M J La, and R Moliner. 2002. "Synergetic Effects in the Co-Pyrolysis of Samca Coal and a Model Aliphatic Compound Studied by Analytical Pyrolysis" 65: 197-206.

Sun, Peiqin, Mingxing Heng, Shaohui Sun, and Junwu Chen. 2010. "Direct Liquefaction of Paulownia in Hot Compressed Water: Influence of Catalysts." Energy 35 (12): 5421-29. https://doi.org/10.1016/j.energy.2010.07.005.
Toba, Makoto, Yohko Abe, Hidetoshi Kuramochi, Masahiro Osako, T. Mochizuki, and Yuji Yoshimura. 2011. "Hydrodeoxygenation of Waste Vegetable Oil over Sulfide Catalysts." Catalysis Today 164 (1): 533-37. https://doi.org/10.1016/j. cattod.2010.11.049.

Uzoejinwa, Benjamin Bernard, Xiuhua He, Shuang Wang, Abd El-Fatah Abomohra, Yamin $\mathrm{Hu}$, and Qian Wang. 2018. "Co-Pyrolysis of Biomass and Waste Plastics as a Thermochemical Conversion Technology for High-Grade Biofuel Production: Recent Progress and Future Directions Elsewhere Worldwide." Energy Conversion and Management 163 (January): 468-92. https://doi. org/10.1016/j.enconman.2018.02.004. 